\title{
VENTILATORY STRUCTURES IN Cryphocricos barozzii SIGNORET (HETEROPTERA, NAUCOROIDEA)
}

\author{
LOPEZ-RUF, M. L., ${ }^{1}$ PELLERANO, G. N. ${ }^{2}$ and BACHMANN, A. O. ${ }^{3}$ \\ ${ }^{1}$ Museo de La Plata, Departamento de Entomología, Paseo del Bosque, 1900, La Plata, Argentina \\ ${ }^{2}$ Facultad de Ciencias Exactas y Naturales, Departamento de Ciencias Biológicas, Universidad de Buenos \\ Aires. Ciudad Universitaria, Pabellón II, Argentina \\ ${ }^{3}$ Museo Argentino de Ciencias Naturales and Facultad de Ciencias Exactas y Naturales, Departamento de \\ Ciencias Biológicas, Universidad de Buenos Aires, Ciudad Universitaria, Pabellón II, Argentina \\ Correspondence to: Mónica L. Lopez-Ruf, Museo de La Plata, Departamento de Entomología, Paseo del \\ Bosque, 1900, La Plata, Argentina \\ Received November 26, 1998 - Accepted March 9, 1999 - Distributed May 31, 2000
}

(With 8 figures)

\begin{abstract}
Plastron and spiracular features strongly resemble those of Aphelocheirus aestivalis (Fab.), described by Messner et al. (1981). Plastronal foliose hairs, somewhat irregular shaped are regularly distributed in the plastron. Very numerous tiny openigs on sternites an tergites connect platronal air with a subcuticular air film limited internally apparently by a membrane. Aplicated, radial, structure at the proximal end of the tracheae, almost occluding the extremely fine spiracular openings, appear with lesser variations in both species, suggesting close relationships than accepted until now.
\end{abstract}

Key words: insect morphology, spiracles, taxonomy, entomology, heteroptera, naucoroidea.

\section{RESUMO}

\section{Estruturas ventilatórias em Cryphocricos barozzii Signoret (Heteroptera: Naucoroidea)}

Descrevem-se estruturas muito semelhantes às de Aphelocheirus aestivalis (Fab.) (Messner et al., 1981). Os pêlos plastronais têm forma de folha e encontram-se distribuídos regularmente no plastron. Aberturas muito pequenas nos esternitos e tergitos conectam o ar plastronal com o ar subcuticular, e estão limitadas internamente por uma membrana. A estrutura na zona próxima à traquéia é similar nas duas espécies comparadas, sugerindo relações mais próximas que as aceitas até agora.

Palavras-chave: morfologia de insetos, espiráculos, taxonomia, entomologia, heteroptera, naucoroidea.

\section{INTRODUCTION}

The species of the Neotropical genus Cryphocricos are of scientific interest owing to their very peculiar morphological features. Moreover, C. barozzii Signoret lives in large streams, in an apparently very restricted environment with swift-flowing water, high turbidity, and at a depth often exceeding three meters. One of the authors (M.L.R.) has found many specimens, both adults and larvae, at exceptional low water level, on small ferruginous sandstone islands emerging from the Paraná River near Paso de la Patria (Corrientes
Province). In field the adults of $C$. barozzii present a shiny air film covering the 'sensorial organs' on their venter; the remaining of the plastron, if present, was not visible. Larvae displayed no such shiny areas. Parsons \& Hewson (1975) reported that Polhemus (personal communication) had seen the same shiny air film in adults of another species of Cryphocricos.

Literature concerning $C$. barozzii is scarce; in most papers this name was applied to other species, frequently not recognized with the available data. The species was rediscovered and recorded for the first time from Argentina by López Ruf 
(1987); thereafter it was redescribed, including its larvae, along with other species from Argentina (López Ruf, 1991, 1996).

Parsons \& Hewson (1975) investigated two species of Cryphocricos and one of Aphelocheirus; the species reported as $C$. barozzii is erroneously identified. In their figure 1 the spiracles are shown very close to the 'sensory organs' they describe in the text. Besides, they say that the second pair of abdominal spiracles and the 'sensorial organs' are hidden under the covering of foliose setae, as on the other urites. Finally these authors mention that Thorp \& Crisp (1947) reported "elongate setae" at the 'sensorial organs' of Aphelocheirus aestivalis (Fab.), which would be compressed by the increased pressure, so stimulating less interposed setae and warning the insect against 'dangerous' depth.

Among the scarce literature concerning fine details of the ventilatory structures in this group, it is relevant to mention the paper of Messner et al. (1981) on A. aestivalis (Fab.) (Naucoroidea, Aphelocheiridae) from Europe. These authors studied specimens which had died and decomposed slowly in their natural, cold water environment, where bacteria had destroyed all but cuticular structures, and so they were able to examine extremely fine features under a scanning electronic microscope (SEM), so avoiding more destructive procedures. They mention the radially arranged canalicula, previously described by Szabó-Patay (1924), which converge to the spiracles, perimetrally formed only by plastronal setae, and which centripetally become deeper and deeper until they close as tubes. These tubes, leading to the spiracular atrium, are well visible at the inner surface of the sclerite. In addition, they mention a very thin subcuticular space beneath tergites and sternites, including the thoracic ones and those of the head. This space is internally limited by an extremely thin 'chitinous' membrane, which would be destroyed by strong treatment. The above mentioned space connects to the outer surface (to the plastron) through extremely fine campaniform (bell-shaped) holes, with the widest diameter at the outer side, and is also connected to the remaining of the tracheal system through fine and medium-sized tracheae. These authors do not explain the origin of this membrane, whose nature must be searched out by other methods. In addition they describe "openings" in the plastron, devoid of foliose setae, which connect with the plastronal air-system and with the subcuticular space. Finally, they describe a small crateriform opening at the center of the spiracular scar.

The life conditions of $C$. barozzii, not enabling it to reach the water surface for very long periods, and the occurrence of shiny areas on the urosternites and laterotergites, suggest a very special structure and function of the plastron and the whole oxygen-winning system, perhaps like that of Aphelocheirus. By direct examination of $C$. barozzii we were unable to identify abdominal spiracles with certainty. Previous examination with stereomicroscope, and with scanning electronic microscope (SEM) produced no convincing results either. Therefore, we decided to study these structures with combined techniques, as did Messner et al. (1981), including histological and, for the first time, clarification methods, which allowed us to examine some structures more accurately.

\section{MATERIAL AND METHODS}

Materials examined: 8 adults, Prov. Corrientes: Paso de la Patria 23.IX.1991, leg. M. L. López Ruf.

The specimens were preserved in field with $70 \%$ ethyl alcohol. For the examination with SEM the abdominal sternites were immersed in a mixture of $96^{\circ} \mathrm{GL}$ ethyl alcohol (70\%), ethyl acetate (20\%), and benzene $(10 \%)$ and cleaned for four minutes in an ultrasonic cleaner. For the examination of the inner surface the soft tissues were removed by keeping the sternites five days in $5 \%$ potassium hydroxide at room temperature, neutralized with alcohol-phenol, and washed with abundant tap water. As this procedure did not result in a satisfactory cleanness, some specimens were put in pond water for three days, in order to inoculate them with saprophytic bacteria, rinsed with tap water, and left therein for nine months; in winter they were put in a laboratory stove at $30-32^{\circ} \mathrm{C}$, so facilitating bacterial action. This method was intended to preserve the delicate cuticular structures, which would be deteriorated with the alkali technique, which is faster but more aggressive. Finally, they were metallized with gold-palladium and photographed with a SEM Jeol T 100. In 
addition the material was examined and photographed with an environmental scanning electronic microscope (ESEM), which operates at high pressure, and allowed us to better analyze delicate structures.

For the examination of the cleared materials with the optic microscope, the abdominal segments of alcohol-fixed specimens were removed, the sternites and latero-tergites were treated with hot $5 \%$ sodium hydroxide, washed with tap water, neutralized and dehydrated for 15 minutes with alcohol-phenol, and cleared and mounted in creosote.

Some specimens were fixed in field for 18 hours in Bouin mixture and preserved in 70\% ethyl alcohol; thereafter, they were dehydrated in alcohol of increasing concentrations and included in paraplast, using butil alcohol as an intermediate medium, serially cut at 6-8 $\mu$, and stained following the Masson method.

\section{RESULTS AND DISCUSION}

With SEM, cuticular structures, apparently setae, were observed, like those seen in two species of Cryphocricos and one of Aphelocheirus by Parsons \& Hewson (1975). The venter is covered by foliose setae (Fig. 5) with a thin pedicel encircled at its base by a small socle and arranged in more or less regular rows. In the plastron some irregularly shaped, small areas devoid of foliose setae are seen, regularly arranged near the spiracles. Some of the modified setal types described by these authors were also observed, covering the abdominal venter.

At longitudinal histological sections of the spiracle (Fig. 1) a series of canalicula formed by radially arranged cuticular foldings was observed (Fig. 2) (in transverse sections they look like a rosette), covered by fine plastronal air-conveying setae.

In cleared preparations a festooned scar-like structure was observed in relation to the spiracle and its outer connection, formed by the tightest foldings of the rosette (Fig. 3). About the same pattern had been reported for Aphelocheirus by Messner et al. (1981).

With the ESEM, the spiracular atrium appears dome-shaped, extending itself beneath the sulci of the rosette (Fig. 4), limited externally by cuticle with furrows and openings. Internally the atrium has longer and thicker setae of plastronal type, and a trachea leads to it. The atrium, with convex proximal surface, has an opening that corresponds to the tracheal one, at the site where the cut plastronal setae appear.

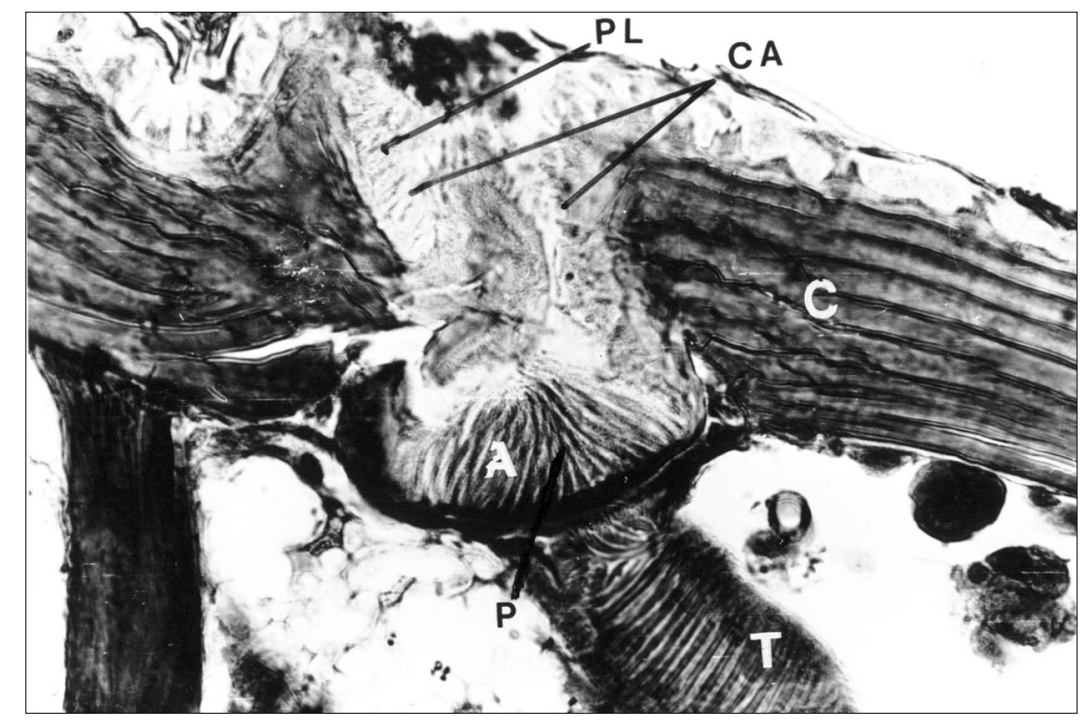

Fig. 1 - Longitudinal section of an spiracle (optic microscope, $630 \mathrm{X}$ ). 


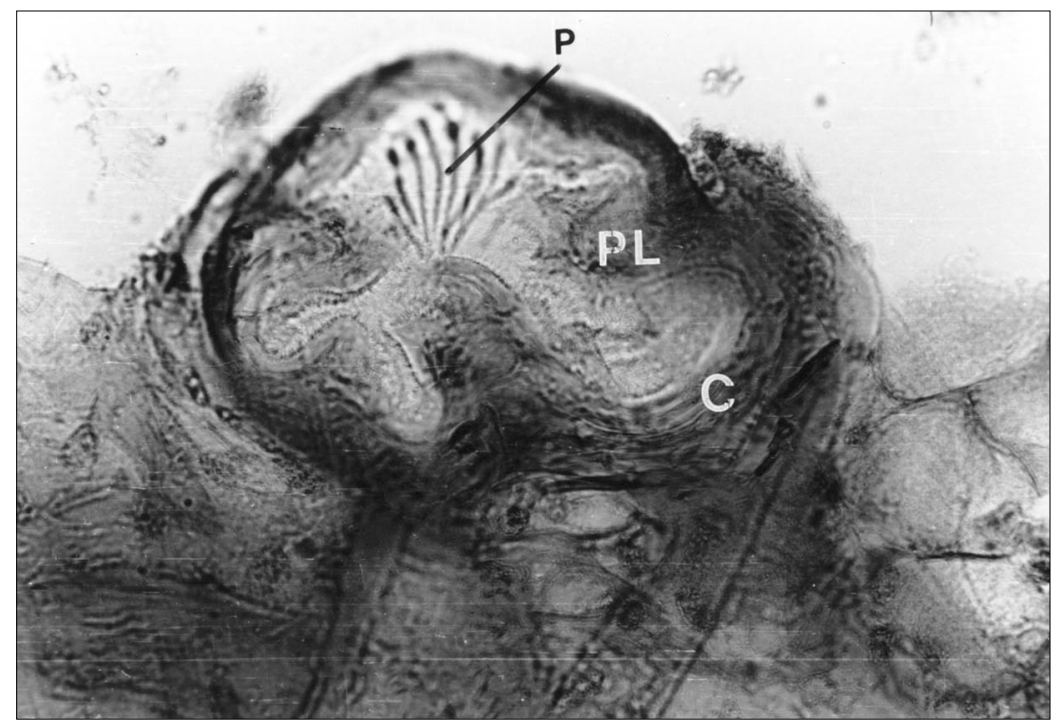

Fig. 2 - Transverse section of a rosette (optic microscope, $630 \mathrm{X}$ ).

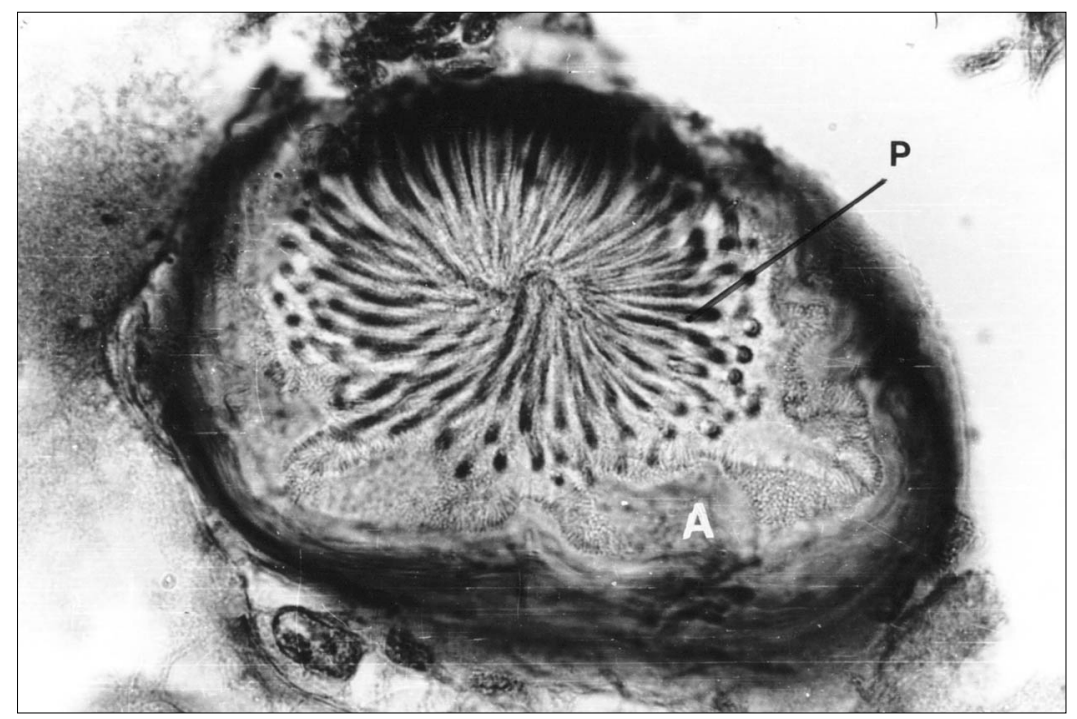

Fig. 3 - Transverse section of an atrium (optic microscope, $630 \mathrm{X}$ ).

Moreover the 'openings' (bare areas) in the plastron, grouped close to the spiracles (Fig. 5), are like those mentioned by Messner et al. (1981) for A. aestivalis. Externally there are polygonal structures without setal insertions, resembling a reticulum (Figs. 5, 7). In Fig. 8 the relation of the bare areas with the foliose setae is shown. In the places where the setae were removed these structures became evident.
With the SEM, cuticular holes were observed, both at the inner and at the outer surfaces of the abdominal sclerites (Fig. 6), also like those mentioned by Messner et al. (1981), but these are more uniform in diameter, i. e. not so markedly bell-shaped.

Neither the histological sections nor the SEM photographs show a chitinous membrane limiting a thin subcuticular air space. 


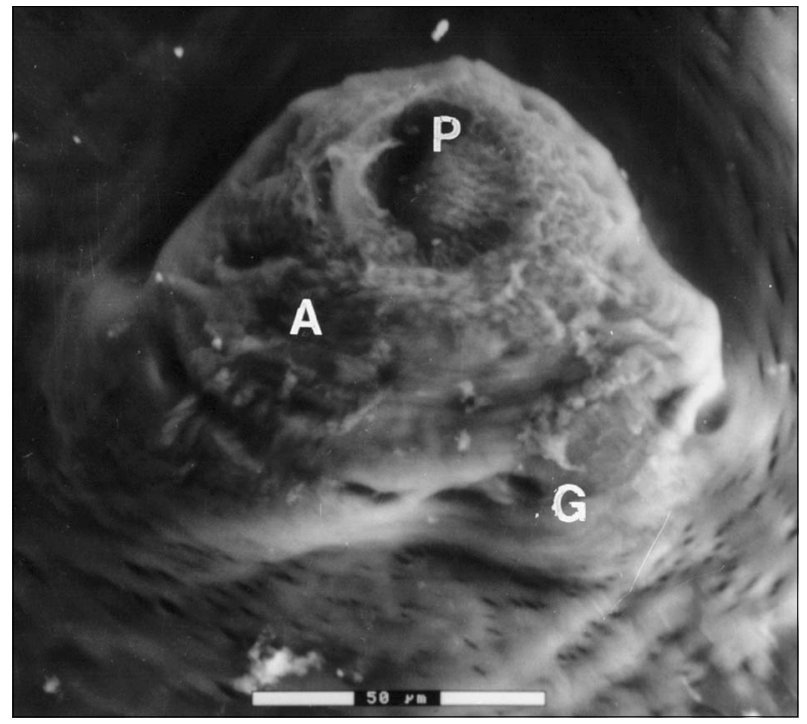

Fig. 4 - Atrium and plastronal setae (ESEM, $650 \mathrm{X})$.

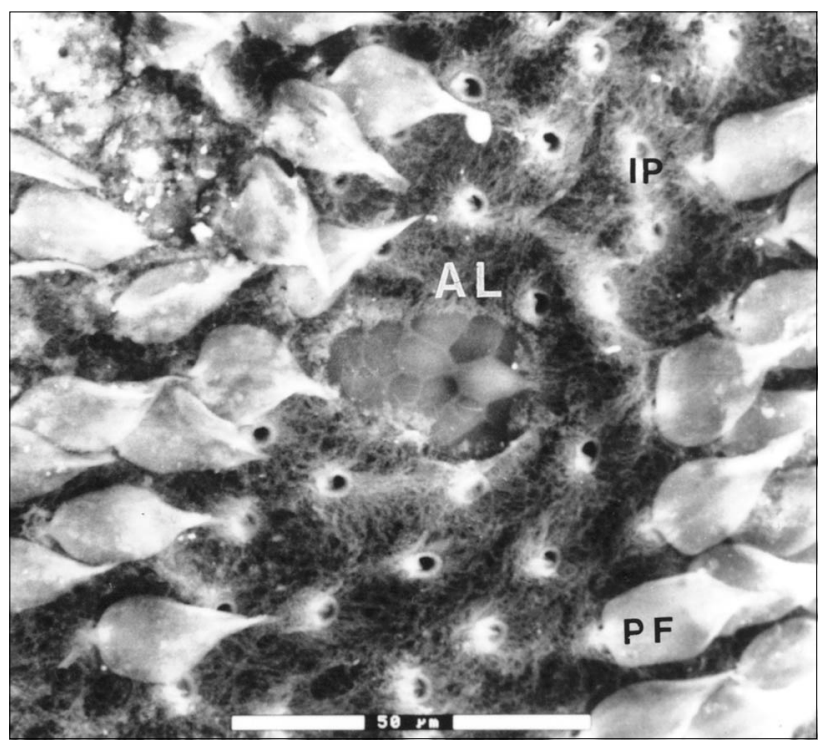

Fig. 5 - Foliose setae and bare areas on venter (ESEM, $800 \mathrm{X}$ ).

\section{CONCLUSIONS}

From the observations made with these combined techniques it is clear that $C$. barozzii has a complex spiracular system, which differs little from that of A. aestivalis. Here, also, there are minute spiracular openings, whose internal portion is filled by a folded, radiated structure, like a plug. A dome-shaped atrium is shown in C. barozzii for the first time, beset by plastronal setae. Here, as is the case of A. aestivalis, spiracles and atria seem to connect with an external air film (plastron) retained by foliose setae.

The thin 'chitinous' membrane seen by Messner et al. (1981) in A. aestivalis was not observed in $C$. barozzii, in spite of having treated the specimens with similar techniques as Messner et al. did. 


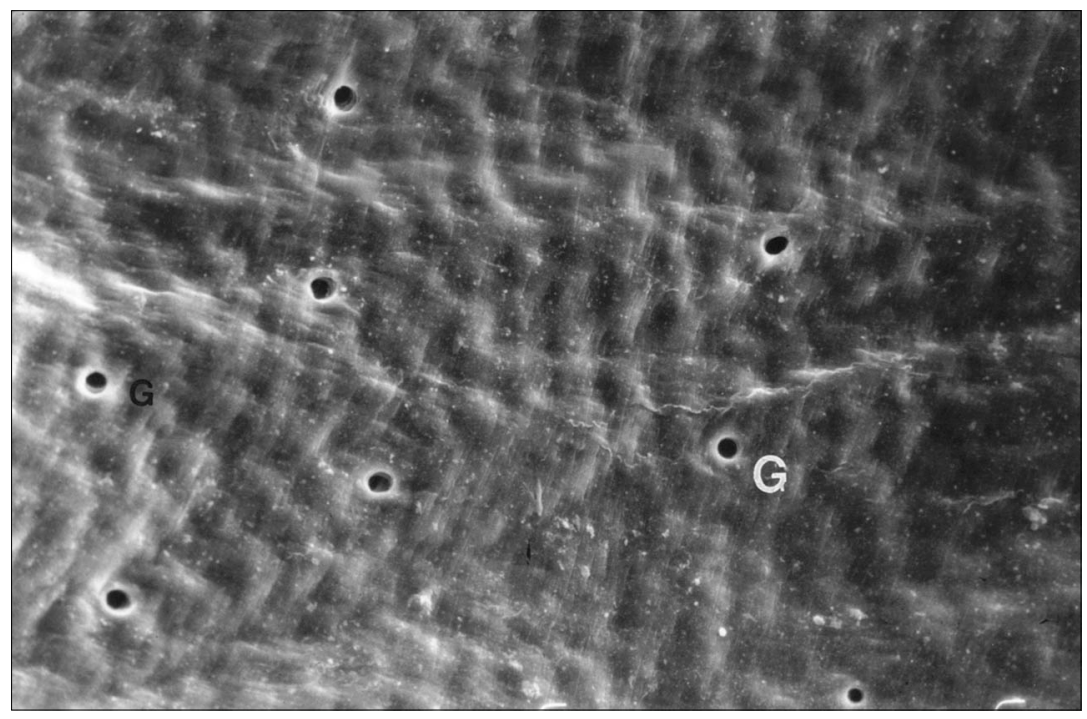

Fig. 6 - Cuticular holes, internal view (SEM, $500 \mathrm{X}$ ).

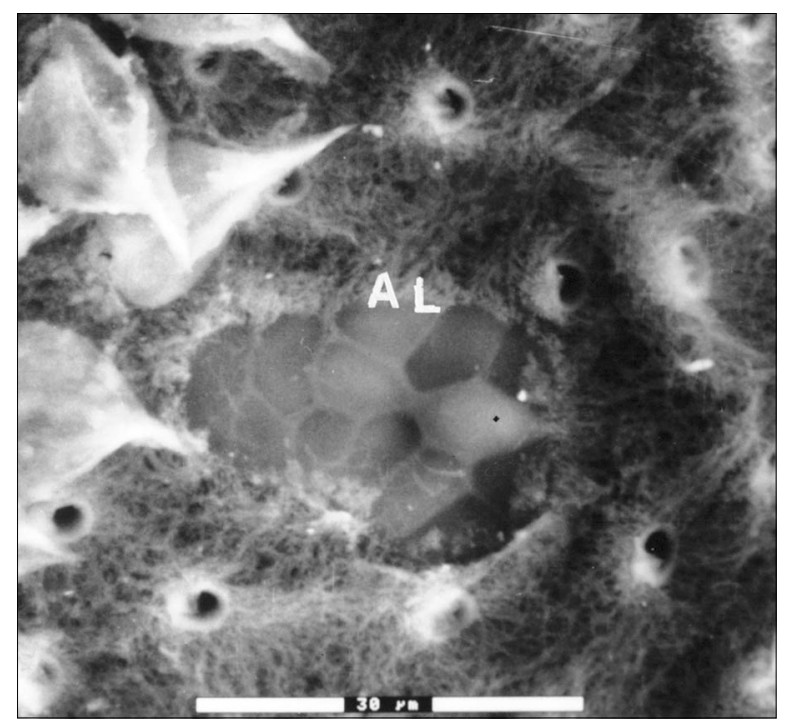

Fig. 7 - Detail of bare area surrounded by setal insertions (ESEM, $1400 \mathrm{X}$ ).

As a conclusion, both species share very similar, highly specialized ventilatory structures. We suggest that such a close resemblance can hardly be due to convergence, leading to similar adaptations for life in an environment without access to atmospheric air, and that both genera are closer related than it was previously supposed. Preliminary observations, which will be extended elsewhere, show a somewhat different covering of the abdominal venter in other species of Cryphocricos from Argentina. These species live in environments which, although lotic, are quite different. 


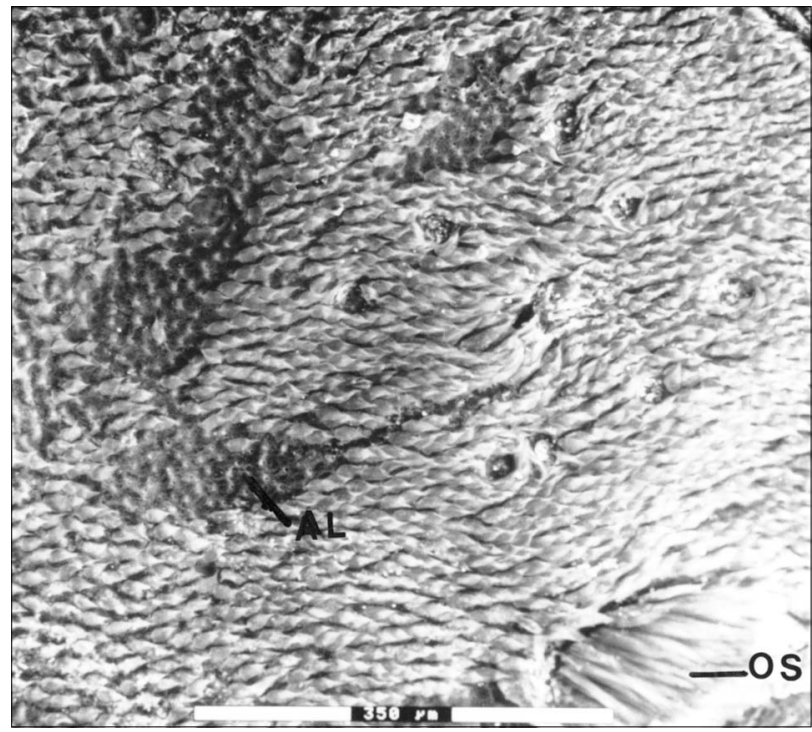

Fig. 8 - General ventral view with 'sensorial organs', and bare areas surrounded by setae (ESEM, $135 \mathrm{X}$ ).

Aknowledgments - We aknowledge the Facultad de Ciencias Naturales y Museo, University of La Plata, for the use of the SEM, and CITEFA (Ciencia y Técnica de las Fuerzas Armadas), for the use of the ESEM.

\section{REFERENCES}

LOPEZ RUF, M. L., 1987, Nuevas citas para la Argentina de especies de Limnocoridae y Naucoridae (Heteroptera). Physis, Secc. B., 45(109): 76.

LOPEZ RUF, M. L., 1991, El Género Cryphocricos en la Argentina. (Hemiptera-Limnocoridae). Rev. Soc. Entom. Argent., 49(1-4) 1991(90): 103-120, f. 1-41.

LOPEZ RUF, M. L., 1996, Nuevas consideraciones sobre Cryphocricos barozzii Signoret y descripción de la ninfa III (Insecta-Heteroptera-Limnocoridae). Physis Secc. B., 51(120-121), 1993: 7-8, f. 1, 2.
MESSNER, B., LUNK, A., GROTH, I., SUBKLEW, H. J. \& TASCHENBERGER, D., 1981, Neue Befunde zum Atmungssystem der Grundwanze Aphelocheirus aestivalis Fab. (Heteroptera, Hydrocorisae). I. Imagines. Zool. Jb. Anat., 105: 474-496, f. 1-18.

PARSONS, C. \& HEWSON, R. J., 1975, Plastral respiratory devices in adult Cryphocricos (Naucoridae: Heteroptera). Phyche, 81(3-4), 1974: 510-527.

SZABO-PATAY, J., 1924, Sur la morphologie et la fonction de l'appareil respiratoire des Aphelocheirus. Annls. Mus. Nation. Hungar., 21: 33-55.

THORPE, W. H. \& CRISP, D. J., 1947, Studies on plastron respiration. 3. The orientation responses of Aphelocheirus (Hemiptera, Aphelocheiridae (Naucoridae)) in relation to plastron respiration; together with an account of specialized pressure receptors in aquatic insects. J. Exper. Biol., 24: 310-328. 